\title{
Predictors of Delayed Healthcare Seeking Among American Muslim Women
}

\author{
Milkie Vu, MA, ${ }^{1,2}$ Alia Azmat, BA, Tala Radejko, BA, and Aasim I. Padela, MD, MSc ${ }^{1-3}$
}

\begin{abstract}
Background: Delayed care seeking is associated with adverse health outcomes. For Muslim women, delayed care seeking might include religion-related motivations, such as a preference for female clinicians, concerns about preserving modesty, and fatalistic beliefs. Our study assesses associations between religion-related factors and delayed care seeking due to a perceived lack of female clinicians.

Materials and Methods: Surveys were distributed to Muslim women attending mosque and community events in Chicago. Survey items included measures of religiosity, religious fatalism, discrimination, modesty, and alternative medicine utilization and worship practices. The outcome measure asked for levels of agreement to the statement "I have delayed seeking medical care when no woman doctor is available to see me."

Results: Two hundred fifty-four women completed the survey with nearly equal numbers of African Americans (26\%), Arab Americans (33\%), and South Asians (33\%). Fifty-three percent reported delays in care seeking due to a perceived lack of female clinicians. In multivariate analysis adjusting for sociodemographic factors, higher religiosity (odds ratio $[\mathrm{OR}]=5.2, p<0.01)$ and modesty levels $(\mathrm{OR}=1.4, p<0.001)$ were positively associated with delayed care seeking. Having lived in the United States for $>20$ years $(\mathrm{OR}=0.22, p<0.05)$ was negatively associated with delayed care seeking.

Conclusion: Many American Muslim women reported delays in care seeking due to a perceived lack of female clinicians. Women with higher levels of modesty and self-rated religiosity had higher odds of delaying care. Women who had lived in the United States for longer durations had lower odds of delaying care. Our research highlights the need for gender-concordant providers and culturally sensitive care for American Muslims.
\end{abstract}

\section{Introduction}

$\mathbf{P}$ atient Delay is often defined as the time lapse between the recognition that an illness requires medical care and the decision to act on this recognition. ${ }^{1}$ Understanding the predictors of delaying care is important for a multitude of reasons, including the fact that postponing seeking and obtaining medical care are associated with a number of adverse health outcomes, such as longer hospital stays, poorer prognosis, increased psychological distress, and higher mortality rates. ${ }^{2,3}$ Patients who delay seeking medical care may either fail to recognize symptoms that require immediate medical attention or believe their symptoms are not serious. Furthermore, access-related barriers including concern about costs of receiving care and lack of insurance, might also influence delayed healthcare seeking. Furthermore, psychological and cultural factors such as fear of diagnosis and patient preferences to utilize alternative therapies before seeing a healthcare provider can also influence the decision to delay care. ${ }^{4}$

Religious factors that impact timely care seeking are relatively understudied. One religious community that may delay care seeking is American Muslim women. Studies report that American Muslim women have lower utilization across a range of health services compared to other groups,${ }^{5-8}$ suggesting that patient delay might be prevalent as a partial explanation for such health disparities. A number of factors can influence American Muslim women's decision to delay care. For one, a lack of gender-concordant providers can be a barrier to timely care. Studies have shown that American Muslims commonly request a physician of the same gender ${ }^{9}$ and put high value on having a provider of the same gender because of Islamic beliefs. ${ }^{10}$ Closely related to and undergirding the

\footnotetext{
${ }^{1}$ Initiative on Islam and Medicine, Program on Medicine and Religion, Department of Medicine, The University of Chicago, Chicago, Illinois. ${ }^{2}$ Section of Emergency Medicine, Department of Medicine, The University of Chicago, Chicago, Illinois.

${ }^{3}$ MacLean Center for Clinical Medical Ethics, The University of Chicago, Chicago, Illinois.
} 
preference for female clinicians are concerns about maintaining modesty in the healthcare encounter. Modesty concerns have been shown to impede obtaining preventive health screening, with Muslim women being less likely to attend discussions on human papillomavirus testing out of fear and embarrassment. ${ }^{11}$ In a study on cancer beliefs, $25 \%$ of Arab Muslim women participating reported feeling uncomfortable during clinical breast examinations due to worries about modesty. ${ }^{12}$ Moreover, a cross-sectional survey evaluating perspectives on quality care finds that South Asian Muslim women in Chicago perceive physicians' inability to respect modesty concerns to be a barrier to receiving quality care. ${ }^{5}$

Religion-informed fatalistic beliefs about health, or the belief that health outcomes are inevitable and/or predetermined by God, can play a role in American Muslim women's decision to delay care seeking, particularly with preventative cancer screening. ${ }^{13}$ A study on Islamic bioethics suggests that fatalistic beliefs may prevent seeking treatment if illness is considered penance for one's sins, or if a woman believes that, irrespective of personal choices, a disease is "fated" for her. ${ }^{14}$ However, the role fatalism plays in the decision to delay or forgo medical care is still inconclusive. A study with 53 Afghan immigrant women's attitudes toward breast cancer screening did not find any support that fatalistic beliefs about health prevented women from obtaining screening. ${ }^{15}$

Finally, a lack of trust and unfamiliarity with the healthcare system, ${ }^{5,16}$ perceived religious discrimination, ${ }^{17}$ and the usage of alternative medicine and religious worship practices for health purpose ${ }^{18}$ may also impact care seeking behaviors in the Muslim community.

While research on American Muslim women is still nascent, our brief review of the literature demonstrates the difficulty in capturing and synthesizing health behaviors in this population. Even though American Muslims are a growing population numbering between 5 and 7 million ${ }^{19-21}$ and comprising diverse ethnicities, including African Americans (35\%), Arabs $(25 \%-30 \%)$, and South Asians $(20 \%-25 \%),{ }^{21,22}$ currently, the overwhelming majority of publications on the American Muslim population are fragmented by ethnic and not religious lines. Moreover, much of the work on Muslim women's health behaviors thus far has been limited to breast cancer, cervical cancer, and HPV screening practices. ${ }^{7,11,12,16,23}$ Although these studies provide some evidence on factors associated with delaying medical care in American Muslim women, they are disease-specific and focus on a restricted spectrum of care (mainly preventive screening), thus being confined in their ability to explore factors associated with delayed care in a more general healthcare context.

Given the centrality of religion to this group's identity and their religion-informed preference for female providers, the present study aimed to explore religion-related factors and sociodemographic characteristics that are associated with delayed care seeking among American Muslim women due to a perceived lack of female clinicians. Based on the literature, we hypothesize that religiosity, fatalistic beliefs regarding healthcare, perceived religious discrimination in healthcare encounters, modesty, and usage of complementary alternative medicine and worship practices for health will be factors potentially impacting this outcome. Furthermore, since no study has quantified the prevalence of delayed care seeking among American Muslim women due to a perceived lack of female clinicians, we aimed to identify this prevalence.

\section{Materials and Methods}

\section{Participant recruitment and data collection}

This study was conducted as part of a larger project on women's attitudes and practices toward preventive health and cancer screening. Detailed descriptions of our participant recruitment and data collection process are described elsewhere. $^{24,25}$ Briefly, we use a community-based participatory research approach ${ }^{26}$ in collaboration with the Council of Islamic Organizations of Greater Chicago (CIOGC), a federation of over 60 mosques, Muslim community centers, and social services, and through forming a Community Advisory Board (CAB) with prominent leaders from Muslim civic organizations. The CAB oversaw all aspects of the study, including study design, survey instrument, data collection, data interpretation, and result dissemination. Our purposive sampling focused on identifying English-speaking, adult, selfidentified Muslim women over the age of 40 attending worship services at mosques and attending Muslim community events hosted by CIOGC partners. As we sought to achieve nearequal representation of Arab, South Asian, and African American Muslims, our recruitment sites were rotated to achieve ethnic/racial diversity. This study was approved by the University of Chicago's Institutional Review Board.

\section{Survey instrument}

Dependent variables. Our primary outcome variable asked women to indicate their level of agreement along a four-point scale to the statement: "I have delayed seeking medical care when no woman doctor is available to see me."

Independent variables. Religiosity. Religiosity was measured using four different previously validated survey items and scales. (i) The self-rating of religiosity asks respondents to rate their religiosity along a 10-point scale and has been used in studies on religiosity and health outcomes of Arabicspeaking respondents. ${ }^{27,28}$ (ii) One item from the Hoge Intrinsic Religious Motivation Scale ${ }^{29}$ was incorporated, which asked participants to indicate their level of agreement to the following statement: "I try hard to carry my religious beliefs over into all my other dealings in life." This item has been used in previous studies on religious characteristics of American physicians. ${ }^{30,31}$ (iii, iv) Two subscales from the Psychological Measure of Islamic Religiousness (PMIR) were included ${ }^{32}$; the seven-item PMIR-Positive Religious Coping and Identification subscale assessed the extent to which respondents rely on religious coping to deal with life stressors, for example: "When facing a health problem, I seek Allah's love and care." The three-item PMIR-Punishing Allah Reappraisal subscale assessed whether respondents interpret illnesses or health problems as a result of God's punishment. For example, an item in the PMIRPunishing Allah Reappraisal subscale asked respondents to indicate their agreement with the statement: "When facing a health problem, I wonder what I did for Allah to punish me." The PMIR was previously validated in an international sample of 340 Muslims. ${ }^{32}$ In our sample, the Positive Religious Coping and Identification subscale had a Cronbach $\alpha$ of 0.89 , and the Punishing Allah Reappraisal subscale had an $\alpha$ of 0.79 .

Religious fatalism. To assess fatalism, two subscales from the previously validated Religious Health Fatalism Questionnaire (RHFQ) were also included. The Divine 
Provision Subscale measured the belief that God will provide good health and included items such as "If a person has enough faith, healing will occur without doctors having to do anything." The Destined Plan Subscale measured the belief that an individual's health status is part of a plan determined by God and included items such as "If I become ill, Allah has intended that to happen." 13 RHFQ was developed with the African American faith community and was used in other studies looking at faith leaders and faith-based health programming and counseling. ${ }^{13}$ We deployed 2 items from each subscale in our survey. The original item wording was modified for a Muslim context by indicating to respondents that statements in the subscales refer to Allah and Islam. ${ }^{33,34}$ In our sample, the RHFQ-Divine Provision had an $\alpha$ of 0.64 and the RHFQ-Destined Plan had an $\alpha$ of 0.85 .

Perceived religious discrimination in healthcare setting. To assess perceived religious discrimination in healthcare, we used the seven-item Discrimination in Medical Settings scale, which assesses the respondents' perceptions of discrimination as well as the frequency with which respondents experience being treated with less courtesy, respect, and receiving poorer medical service than others. The measure was previously used in a study looking at the interactions between African American patients and healthcare providers. ${ }^{35} \mathrm{We}$ adapted the scale by replacing the words "other people or others" with "non-Muslims" on three items. The Perceived Discrimination measure has an $\alpha$ of 0.93 in our sample.

Islamic modesty. We investigated levels of Islamic modesty through a series of 5 questions that are part of a previously published Islamic modesty scale. ${ }^{24}$ The scale was developed using qualitative data on healthcare accommodations requested by American Muslims. ${ }^{36}$ The 5 items together had an $\alpha$ of 0.80 in our sample. (See Table 1 for a complete list of the 5 questions used to assess levels of Islamic modesty).

Usage of Islam-related complementary alternative medicines and worship practices for health. Using previous qualitative data, ${ }^{36,37}$ we developed two measures of Alternative Medicine Usage and Worship Practices. The first measure assessed the frequency with which Muslims utilize certain healing practices based on scriptural source texts or Muslim culture when faced with illnesses or a health problem. ${ }^{37}$ For example, items assessed frequency of using Prophetic Medicine (i.e., honey, black seed, cupping) or consulting practitioners of traditional methods of Islamic healing. For Worship Practices, we included items such as performing extra fasts and prayer and

Table 1. Selected Items Used to Assess ISLAMIC MODESTY

\footnotetext{
Question stem

When I am in a mixed sex gathering or outside the home, I cover my entire body, except my hands and face.

When I have guests at my home, men and women sit separately.

An unmarried man and unmarried woman should not be alone together.

My clothing demonstrates a commitment to Islamic modesty.

Maintaining Islamic modesty is important to me.
}

reading extra amount of Qu'ran when facing health problems. The Usage of Islam-related Complementary Alternative Medicines and Worship Practices for Health measures had an $\alpha$ of 0.63 and 0.82 , respectively, in our sample.

Sociodemographic variables. We included survey items on factors known to influence health beliefs and care seeking behaviors such as insurance status, having a primary care physician, and duration of living in the United States. Additional sociodemographic characteristics included age, ethnicity, country of origin, level of educational attainment, and annual household income.

\section{Data analyses}

Two research assistants independently entered survey data into Research Electronic Data Capture software, ${ }^{38}$ resolving discrepancies by referring to original surveys.

We transformed several variables for ease of interpretation. Summed scores for the PMIR subscales, RHFQ subscales, and Perceived Religious Discrimination in Healthcare, Islamic Modesty, Usage of Islam-related Complementary Alternative Medicines, and Worship Practices for Health scales were transformed by assigning each response category a numerical value between 0 and 10 . For these scales and subscales, average scores were calculated if a respondent answered more than $50 \%$ of the items within each scale. The responses for the outcome variable were dichotomized into a binary outcome of "completely/somewhat agree" and "completely/somewhat disagree." Because of the skewed distribution of the variable of self-rating religiosity, it was transformed from a continuous to a categorical variable: "very religious" was defined as a level between 8 and 10 on a 10-point scale, "moderately religious" defined as a level of 6 or 7, and "somewhat or not religious" as a level between 0 and 5 .

Using STATA 13 software (College Station, TX), we obtained Cronbach $\alpha$ for our measures to verify internal consistency. We used logistic regression models to test for associations between the all independent and dependent variables and thereby obtain models adjusting odds ratios (ORs). Religion-related independent variables found associated with the outcome at the level of $p<0.1$ in bivariate testing were placed into single multivariate models, adjusted for sociodemographic characteristics found to be significantly associated with the outcome $(p<0.1)$ to obtain adjusted ORs. A "complete" multivariate model contained all of the religion-related variables found to be significant after controlling for sociodemographic characteristics in separate equations (as described previously) as well as the significant sociodemographic independent variables in a single equation. To avoid multicollinearity, we computed the Pearson product moment correlation coefficient between age and living duration in the United States and the Spearman's rank correlation coefficient between self-rated religiosity and modesty to make sure these variables are not highly correlated before placing them into the multivariate model.

\section{Results \\ Participant characteristics}

Two hundred fifty-four women completed the survey, with nearly equal numbers of African Americans (26\%), Arab 
Table 2. Sociodemographic Characteristics of Participants $(N=254)$

\begin{tabular}{|c|c|}
\hline Characteristic & $\mathrm{N}(\%)$ \\
\hline \multicolumn{2}{|l|}{ Age, $N=220$} \\
\hline$<40$ & $14(6.5)$ \\
\hline $40-49$ & 89 (40.4) \\
\hline $50-74$ & $108(49.1)$ \\
\hline$\geq 75$ & $9(4.1)$ \\
\hline Median (range) & $50(25-85)$ \\
\hline \multicolumn{2}{|l|}{ Racial/ethnic background, $N=233$} \\
\hline Arab/Arab American & $77(33.1)$ \\
\hline African American/Black & $60(25.8)$ \\
\hline South Asian & $78(33.5)$ \\
\hline \multicolumn{2}{|l|}{ Country of origin, $N=240$} \\
\hline US & $77(32.1)$ \\
\hline Other & $163(67.9)$ \\
\hline India & $30(12.5)$ \\
\hline Jordan & $14(5.8)$ \\
\hline Pakistan & $30(12.5)$ \\
\hline Palestine & $36(15.0)$ \\
\hline \multicolumn{2}{|l|}{ Duration in the United States (years), $N=239$} \\
\hline$\leq 10$ & $38(15.9)$ \\
\hline $11-20$ & $45(18.8)$ \\
\hline$>20$ & $156(65.3)$ \\
\hline \multicolumn{2}{|l|}{ Marital status, $N=237$} \\
\hline Married & $174(73.4)$ \\
\hline \multicolumn{2}{|l|}{ Highest level of education, $N=236$} \\
\hline Less than high school & $32(13.6)$ \\
\hline High school & $55(23.3)$ \\
\hline Associates & $54(22.9)$ \\
\hline Bachelors & $57(24.2)$ \\
\hline Advanced degree & $38(16.1)$ \\
\hline \multicolumn{2}{|l|}{ Annual household income, $N=225$} \\
\hline$\leq \$ 45,000$ & $129(57.3)$ \\
\hline$\$ 45,001-\$ 105,000$ & $67(29.8)$ \\
\hline$\geq \$ 105,001$ & $29(12.9)$ \\
\hline Have health insurance, $N=238$ & $181(76.1)$ \\
\hline Have primary care physician access, $N=246$ & $208(84.6)$ \\
\hline $\begin{array}{l}\text { Delayed seeking healthcare when } \\
\text { no female physician is available, } N=242\end{array}$ & $129(53.3)$ \\
\hline
\end{tabular}

Americans (33\%), and South Asians (34\%). Respondents' median age was 50 . One hundred fifty-six respondents $(65 \%)$ had lived in the United States for more than 20 years. Most respondents in our sample had health insurance and access to a primary care physician (76\% and $85 \%$, respectively) (See Table 2).

For the primary outcome of interest, 129 respondents $(53 \%)$ reported delayed care seeking due to a perceived lack of female clinicians.

\section{Associations between survey measures and delayed care seeking due to a perceived lack of female clinicians (See Table 3)}

Religiosity. One hundred fifty-eight respondents (70\%) self-rated to be "very religious" and 35 respondents $(16 \%)$ considered themselves "moderately religious."

On bivariate analysis, participants with higher levels of selfrated religiosity (ORs between 4.2 and 5.5, $p<0.01$ ) had higher odds of delaying care. This relationship remained significant in the multivariate model after adjusting for sociodemographic variables (Model A: ORs between 3.9 and 7.0, $p<0.05$ ). In the final multivariate model, participants with the highest level of self-rated religiosity ("very religious") had higher odds of delaying care (Model F: $\mathrm{OR}=5.2, p<0.01$ ).

The PMIR-Punishing Allah Reappraisal $(\mathrm{OR}=1.01, p<0.05)$ subscale was significantly associated with the independent variable on bivariate analysis, but not in the multivariate model adjusting for sociodemographic variables (Model B).

Religious fatalism. One hundred thirteen respondents (49\%) indicated agreement to the statement "I do not worry about my health because it is in Allah's hands."

The RHFQ: Divine Provision scale was positively associated with the independent variable on bivariate analysis $(\mathrm{OR}=1.01, p<0.05)$, but this relationship was not maintained after adjusting for sociodemographic variables (Model C). The RHFQ: Destined Plan subscale was not significantly associated with the outcome.

Perceived religious discrimination in healthcare. Perceived religious discrimination $(\mathrm{OR}=1.01, p<0.05)$ was positively associated with the independent variable on bivariate analysis, but was found to be nonsignificant after adjusting for sociodemographic variables (Model D).

Islamic modesty. Two hundred twenty-four respondents (93\%) agreed with the statement "Maintaining Islamic modesty is important to me." On bivariate analysis, participants with a higher level of modesty $(\mathrm{OR}=1.4, p<0.001)$ had higher odds of delaying care. This relationship was maintained in multivariate models (Model E: $\mathrm{OR}=1.5, p<0.001$; Model F: $\mathrm{OR}=1.4, p<0.001)$.

Usage of Islam-related complementary alternative medicines and worship practices for health. Both scales of Usage of Islam-related Complementary Alternative Medicines and Worship Practices for Health were not significant on bivariate analysis.

Sociodemographic variables. Participants who had lived in the United States for more than 20 years had lower odds of delaying care. This relationship was maintained in bivariate and all multivariate models, including the final multivariate model (Model F: OR=0.22, $p<0.05$ ). No other sociodemographic factor was significantly associated with the dependent variable in multivariate models.

\section{Discussion}

Our study of a community-based sample of 254 Muslim women from diverse ethnic and racial backgrounds yielded several interesting findings. We found that the majority of our respondents report delayed care seeking due to a perceived lack of female clinicians. Women with higher levels of modesty and highest level of self-rated religiosity had higher odds of delaying seeking care, while those who had resided in the United States for more than 20 years had lower odds. Notably, contrary to our hypothesis, we did not find significant associations between the decision to delay care seeking and religious fatalism or perceived experiences of religious discrimination in healthcare.

A substantial number of participants- $53 \%$ of our samplereported delays in care seeking. This result suggests that a significant portion of American Muslim women may delay 


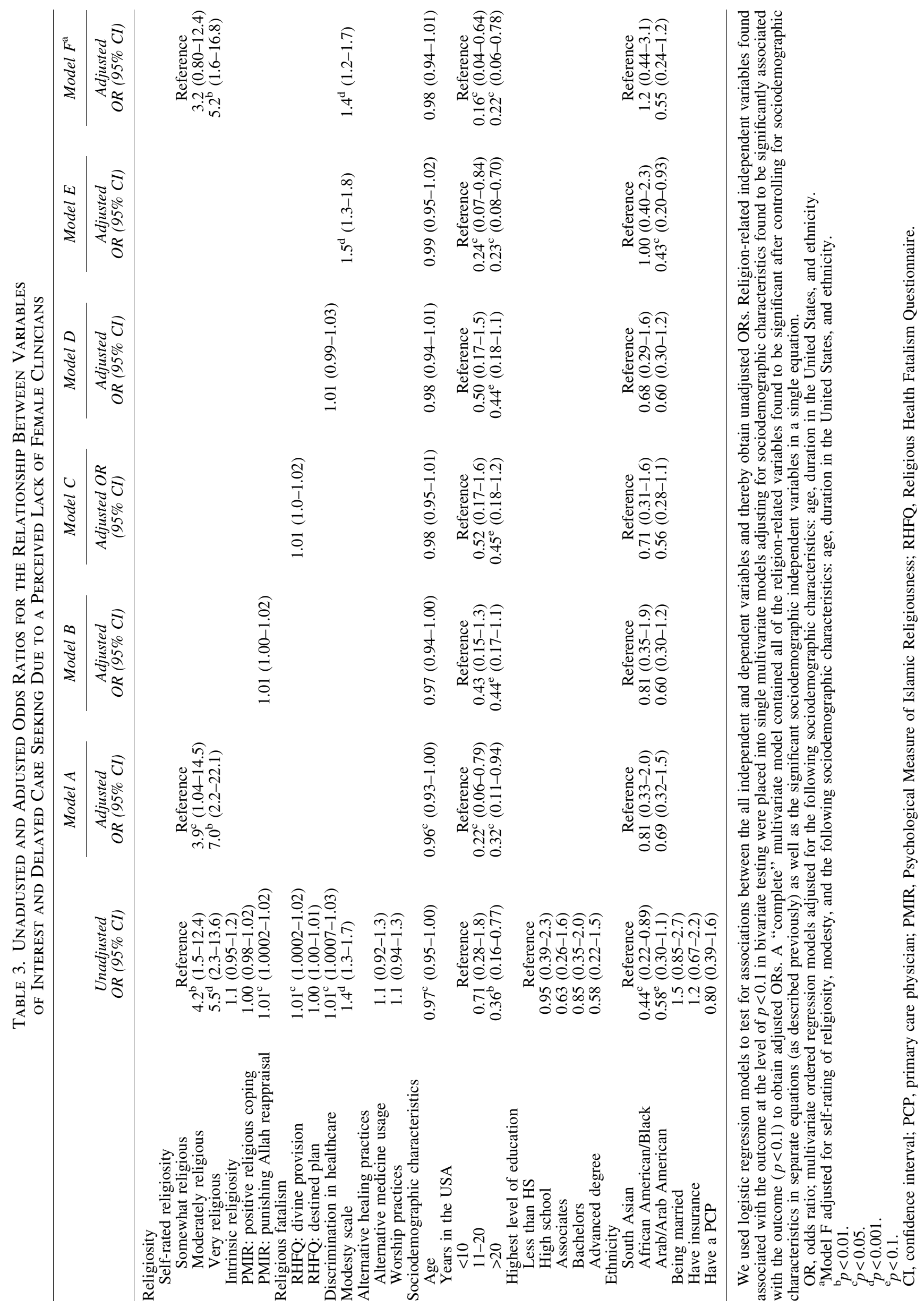


or forgo care due to a perceived lack of female clinicians. Delayed care seeking is associated with deleterious health outcomes - specifically lower survival rates for women with breast cancer ${ }^{39}$ and impaired fertility in women with pelvic inflammatory disease. ${ }^{40}$ Consequently, our finding has important implications for healthcare professionals and researchers working to improve women's health and reduce health disparities among American Muslims.

In our study, women with higher levels of self-rated religiosity reported higher odds of delaying seeking care. Religious teachings and Islamic bioethics guidelines may explain why highly religious women prefer to see providers of the same sex. Islamic bioethical prescriptions regarding the hierarchy of practitioners Muslims should seek care from note that physicians of the same gender should be sought before those of the opposite gender. ${ }^{14}$ Moreover, Islamic authorities discourage skin to skin contact such as shaking hands and even being alone with a member of the opposite sex. ${ }^{9}$ Another possible explanation is Muslim women's preference for gender-segregated environments. Separation of genders in public settings, such as the mosque, is common in many Muslim communities. ${ }^{9}$ It is possible that our group of women, sampled from mosques and community organizations, are more comfortable in gender-segregated healthcare environments as well. As such, these religious values may influence womens' decisions to delay seeking care when a female provider is unavailable.

Our results also indicate that highly modest Muslim women have higher odds of delaying care. This finding is expected, in light of our above-detailed discussion of the value Islam places on modesty and gender concordance. Muslim women may perceive that having a male doctor providing healthcare services might comprise their modesty and hence chose to delay medical care if a female provider is not available. Other studies also note that concerns about preserving modesty in the healthcare setting are not limited to the American Muslim population. Chinese, Filipino, and Asian Indian women also report being examined by a male practitioner as a barrier to obtaining mammograms. ${ }^{41}$ For Korean American women with little or no English skills, modesty was also a perceived barrier to getting a mammogram. ${ }^{42}$

We note that in our sample, modesty and self-rated religiosity are independent predictors of the decision to delay care seeking and the measures were not highly correlated. We offer two possible explanations for this observation. First, modesty values might be informed by not just religious understandings, but cultural norms as well. The extant literature supports this hypothesis, as several studies have highlighted how Muslim women distinguish between culture and religion when identifying the source of their understanding of modesty. A study on Arab American women's experiences with cancer screening shows that although women in the study acknowledged that Islam allows for their physical examinations to be performed by men, participants still reported feelings of shame and embarrassment when seen by strangers. ${ }^{12,43}$ Embarrassment has also been reported as a barrier to obtain HPV screening in a study of Muslim women in the United Kingdom, and participants in this study identified "Asian" and not "Muslim" norms (i.e., cultural, not religious norms) regarding discussing sexual activity as the reason for this embarrassment. Second, the lack of correlation between the measures also implies that modesty is only one construct that maps on to our sample's definition of religiosity. Highly religious women most likely considered other virtues of faith as evidence of their piety. Commitment to the faith and self-rated religiosity for our sample may have included other religious actions such as prayers, knowledge of scripture, donating money to the congregation, in addition to, or even outside of observing modesty rules. ${ }^{44}$

We also found that longer duration of living in the United States is associated with lower odds of delaying care. Some researchers have suggested how the social and economic demands of adjusting to a new culture may hinder women from taking care of their health. ${ }^{12}$ Language proficiency and difficulties communicating with providers about health needs may also be a barrier to health service utilization, ${ }^{11}$ especially if women have just recently immigrated. ${ }^{12}$ Women who have lived in the United States longer may have more knowledge and be more comfortable navigating the healthcare system and explaining their religious and cultural values. ${ }^{5}$ As such, women with more experience with the healthcare system may feel more confident when asking for a female provider. In addition, women who have lived for longer periods in the United States may reinterpret Islamic requirements in healthcare encounters. Thus, while they prefer to be seen by female providers, they still seek care even when female providers are not available.

Our study expands the scope of culturally competent care by highlighting how gender-concordant care is an important component of culturally competent care for American Muslim women. Previous studies have recommended providing prayer books, rugs, and compasses, ${ }^{45}$ addressing languagerelated communication barriers, ${ }^{5}$ and providing education on religious and cultural beliefs of Muslim patients to providers. $5,46,47 \mathrm{We}$ extend these recommendations to include providing gender-concordant providers to Muslim women in healthcare settings as far as possible.

Other studies on gender concordance have demonstrated the benefits of female-female patient-provider relationships. Research suggests female providers have better communication styles, spend more time with female patients, and are more likely to engage in patient-centered interactions and "social chat." ${ }^{48,49}$ Moreover, female patients are more likely to initiate preventive services requests, such as breast and pelvic examinations, when they have female providers. ${ }^{48}$ Consequently, American Muslims may feel more comfortable chatting, asking questions, and obtaining breast and pelvic examinations when they are with a provider of the same gender. Healthcare practitioners should be cognizant of the preference for gender-concordant providers, as well as the benefits coming from such relationships for American Muslim women, to enhance care for this population.

In addition, it is important to examine the context of care seeking to accurately provide care to this population. While our study did not inquire whether Muslim women delayed urgent, acute, or preventative care, such research is an important next step to developing targeted educational and policy interventions in the community and the healthcare system. While it may be more difficult for women to see gender concordant providers in the emergency room due to the acuity of patient need, modesty concerns for this population may be upheld in other ways - such as longer hospital gowns. ${ }^{50}$ Hospitals may also make efforts to ensure providers of both sexes are on staff at all times. Religious accommodations can also be made regarding daily prayers, the practice 
of fasting during Ramadan, dietary code, and death-related traditions. ${ }^{50}$ As such, policy interventions may differ based on the environment of care, such as more female staff in ambulatory care, longer gowns in emergency rooms, and cultural competency training for all healthcare providers.

Strengths of our project include our sample of Muslim women from diverse ethnic backgrounds, the use of several previously validated survey instruments, and the inclusion of a wide range of religion-related measures known to influence health behaviors. However, our findings must be interpreted in light of several limitations. Our survey did not specify a definition of patient delay. Participants could have interpreted the question in a number of different ways, such as delaying setting an initial appointment, delaying a follow-up appointment, or delaying annual preventative screening. In addition, our recruiting strategy pulled out a sample of women who were English literate, over the age of 40, and attended the mosque and community events. This strategy may limit the generalizability of findings from our study as these beliefs and behaviors are not representative of all American Muslim women.

\section{Conclusion}

Our work has important implications for women's health and health disparities research. To our knowledge, our study is the first that quantifies the phenomenon of delaying seeking care when no female doctor is available among American Muslim women and characterizes what types of women are more prone to delayed care seeking. Future studies should explore this phenomenon in other groups, specify the clinical context of delayed care seeking, and tease out the patterning of healthcare disparities that may arise from delays in seeking care due to lack of availability of same-sex providers.

\section{Acknowledgments}

This project was supported by an Institutional Research Grant (\#58-004) from the American Cancer Society and a Cancer Center Support Grant (\#P30CA14599). Data warehousing was supported by the RED Cap project at the University of Chicago, managed by the Center for Research Informatics, and funded by the Biological Sciences Division and the Institute for Translational Medicine CTSA Grant (UL1 RR024999). The authors acknowledge the many efforts of their community partners and advisors for their invaluable recruitment assistance and support: Ahlam Jbara and Dr. Zaher Sahloul from the Council of Islamic Organizations of Greater Chicago, Itedal Shalabi from Arab American Family Services, and Dr. Bambade Shakoor-Abdulla of CMECCA. They would also like to thank all of the staff members at their recruitment sites who made data collection possible. Finally, a sincere note of thanks to the research assistants Sohad Murrar, Zahra Hosseinian, and Brigid Adviento and the respondents for taking the time to fill out the survey.

\section{Author Disclosure Statement}

No competing financial interests exist.

\section{References}

1. Andersen BL, Cacioppo JT. Delay in seeking a cancer diagnosis: Delay stages and psychophysiological comparison processes. Br J Soc Psychol 1995;34 (Pt 1):33-52.
2. Walter F, Webster A, Scott S, Emery J. The Andersen Model of Total Patient Delay: A systematic review of its application in cancer diagnosis. J Health Serv Res Policy 2012;17:110-118.

3. Weissman JS, Stern R, Fielding SL, Epstein AM. Delayed access to health care: Risk factors, reasons, and consequences. Ann Intern Med 1991;114:325-331.

4. Nonzee N, Ragas D, Ha Luu T, et al. Delays in cancer care among low-income minorities despite access. J Womens Health (Larchmt) 2015;24:506-514.

5. Hasnain M, Connell KJ, Menon U, Tranmer PA. Patientcentered care for Muslim women: Provider and patient perspectives. J Womens Health (Larchmt) 2011;20:73-83.

6. Abu-Ras W. Cultural beliefs and service utilization by battered Arab immigrant women. Violence Against Women 2007;13:1002-1028.

7. Hasnain M, Menon U, Ferrans CE, Szalacha L. Breast cancer screening practices among first-generation immigrant muslim women. J Womens Health (Larchmt) 2014;23:602612.

8. Hatefnia E, Niknami S, Bazargan M, Mahmoodi M, Lamyianm M, Alavi N. Correlates of mammography utilization among working Muslim Iranian women. Health Care Women Int 2010;31:499-514.

9. Ezenkwele UA, Roodsari GS. Cultural competencies in emergency medicine: Caring for Muslim-American patients from the Middle East. J Emerg Med 2013;45:168-174.

10. Rajaram SS, Rashidi A. Asian-Islamic women and breast cancer screening: A socio-cultural analysis. Women Health 1999;28:45-58.

11. Szarewski A, Cadman L, Ashdown-Barr L, Waller J. Exploring the acceptability of two self-sampling devices for human papillomavirus testing in the cervical screening context: A qualitative study of Muslim women in London. J Med Screen 2009;16:193-198.

12. Salman KF. Health beliefs and practices related to cancer screening among Arab Muslim women in an urban community. Health Care Women Int 2012;33:45-74.

13. Franklin MD, Schlundt DG, Wallston KA. Development and validation of a religious health fatalism measure for the African-American faith community. J Health Psychol 2008;13:323-335.

14. Padela AI, Curlin FA. Religion and disparities: Considering the influences of Islam on the health of American Muslims. J Relig Health 2013;52:1333-1345.

15. Shirazi M, Bloom J, Shirazi A, Popal R. Afghan immigrant women's knowledge and behaviors around breast cancer screening. Psychooncology 2013;22:1705-1717.

16. Raymond NC, Osman W, O'Brien JM, et al. Culturally informed views on cancer screening: A qualitative research study of the differences between older and younger Somali immigrant women. BMC Public Health 2014;14:1188.

17. Shah SM, Ayash C, Pharaon NA, Gany FM. Arab American immigrants in New York: Health Care and cancer knowledge, attitudes, and beliefs. J Immigr Minor Health 2008;10:429-436.

18. Al-Amoudi S, Cañas J, Hohl SD, Distelhorst SR, Thompson B. Breaking the silence: Breast cancer knowledge and beliefs among Somali Muslim women in Seattle, Washington. Health Care Women Int 2015;36:608-616.

19. Ba-Yunus I. Muslims of Illinois: A demographic report. Chicago, IL: East-West University, 1997.

20. Smith TW. The Muslim population of the United States: The methodology of estimates. Public Opin Quart 2002;66:404-417. 
21. Muslim American Demographic Facts. Allied Media Corporation: Multicultural communication. 2000. Available at: www.allied-media.com/AM/ Accessed August 1, 2015.

22. Project TMWF. Muslim Americans: A national portrait. Washington DC, 2009. Available at: www.themosquein morgantown.com/pdfs/GallupAmericanMuslimReport.pdf Accessed August 1, 2015.

23. Matin M, LeBaron S. Attitudes toward cervical cancer screening among Muslim women: A pilot study. Women Health 2004;39:63-77.

24. Padela AI, Murrar S, Adviento B, et al. Associations between religion-related factors and breast cancer screening among American Muslims. J Immigr Minor Health 2015;17:660-669.

25. Padela AI, Peek ME, Johnson-Agbakwu CE, Hosseinian Z, Curlin F. Associations between religion-related factors and cervical cancer screening among Muslims in greater Chicago. J Low Genit Tract Dis 2014;18:326-332.

26. Israel BA, Eng E, Schulz A, Parker EA, Satcher D. Methods in community-based participatory research for health, 1st ed. San Francisco: Jossey-Bass, 2005.

27. Abdel-Khalek AM. Happiness, health, and religiosity: Significant relations. Ment Health Relig Cult 2006;9:85-97.

28. Abdel-Khalek AM. Religiosity, health and happiness: Significant relations in adolescents from Qatar. Int J Soc Psychiatry 2014;60:656-661.

29. Hill P, Hood R. Measures of religiosity, 1999. Available at: www-rohan.sdsu.edu/ mstover/tests/hill.htm Accessed August 1, 2015.

30. Curlin FA, Lantos JD, Roach CJ, Sellergren SA, Chin MH. Religious characteristics of U.S. physicians: A National Survey. J Gen Intern Med 2005;20:629-634.

31. Curlin FA, Dugdale LS, Lantos JD, Chin MH. Do religious physicians disproportionately care for the underserved? Ann Fam Med 2007;5:353-360.

32. Abu Raiya H, Pargament KI, Mahoney A, Stein C. A Psychological Measure of Islamic Religiousness: Development and evidence for reliability and validity. Int $\mathrm{J}$ Psychol Relig 2008;18:291-315.

33. Bopp M, Fallon EA. Individual and institutional influences on faith-based health and wellness programming. Health Educ Res 2011;26:1107-1119.

34. Fallon E, Bopp M, Webb B. Factors associated with faithbased health counselling in the United States: Implications for dissemination of evidence-based behavioural medicine. Health Soc Care Community 2013;21:129-139.

35. Bird S, Bogart L. Perceived race-based and socio-economic status (SES)-based discrimination in interactions with healthcare providers. Ethn Dis 2001;11:554-563.

36. Padela AI, Gunter K, Killawi A, Heisler M. Religious values and healthcare accommodations: Voices from the american muslim community. J Gen Int Med 2012;27:708-715.

37. AlRawi S, Fetters MD, Killawi A, Hammad A, Padela A. Traditional healing practices among American Muslims: Perceptions of community leaders in Southeast Michigan. J Immigr Minor Health 2012;14:489-496.

38. Harris PA, Taylor R, Thielke R, Payne J, Gonzalez N, Conde JG. Research electronic data capture (REDCap)-a metadata-driven methodology and workflow process for providing translational research informatics support. J Biomed Inform 2009;42:377-381.

39. Richards MA, Westcombe AM, Love SB, Littlejohns P, Ramirez AJ. Influence of delay on survival in patients with breast cancer: A systematic review. Lancet 1999;353:11191126.

40. Hillis S, Joesoef R, Marchbanks P, Wasserheit J, Cates WJ, Westrom L. Delayed care of pelvic inflammatory disease as a risk factor for impaired fertility. Am J Obstet Gynecol 1993;168:1503-1509.

41. Wu TY, West B, Chen YW, Hergert C. Health beliefs and practices related to breast cancer screening in Filipino, Chinese and Asian-Indian women. Cancer Detect Prev 2006; 30:58-66.

42. Lee H, Kim J, Han HR. Do cultural factors predict mammography behaviour among Korean immigrants in the USA? J Adv Nurs 2009;65:2574-2584.

43. Azaiza F, Cohen M. Health beliefs and rates of breast cancer screening among Arab women. J Womens Health (Larchmt) 2006;15:520-530.

44. El-Menouar Y, Stiftung B. The five dimensions of Muslim religiosity. Results of an empirical study. Methods Data Analyses 2014;8:53-78.

45. Davidson J, Boyer ML, Caset D, Matzel S, Walden C. Gap analysis of cultural and religious needs of hospitalized patients. Crit Care Nurs Q 2008;31:119-126.

46. Marrone SR. Factors that influence critical care nurses' intentions to provide culturally congruent care to Arab Muslims. J Transcult Nurs 2008;19:8-15.

47. Hill N, Hunt E, Hyrkäs K. Somali immigrant women's health care experiences and beliefs regarding pregnancy and birth in the United States. J Transcult Nurs 2012;23: 72-81.

48. Franks P, Bertakis KD. Physician gender, patient gender, and primary care. J Womens Health (Larchmt) 2004;12: 73-80.

49. Bertakis KD, Franks P, Epstein RM. Patient-centered communication in primary care: Physician and patient gender and gender concordance. J Womens Health (Larchmt) 2009; 18:539-545.

50. Management Sciences for Health. Principles for Culturally Competent Health Care for Muslim Families and Communities 2002. Available at: http://erc.msh.org/mainpage.cfm? file $=5.4 .6 \mathrm{~g} . \mathrm{htm} \&$ module $=$ provider $\&$ language $=$ English $\mathrm{Ac}-$ cessed August 1, 2015.

Address correspondence to: Aasim I. Padela, MD, MSc Section of Emergency Medicine Department of Medicine

The University of Chicago 5841 South Maryland Avenue, MC 5068 Chicago, IL 60637

E-mail: apadela@medicine.bsd.uchicago.edu 